\title{
Challenging the engineering view: comparative analysis of technological and biological functions targeting energy efficient facade systems
}

\author{
S. Gosztonyi ${ }^{1}$, M. Brychta ${ }^{1} \&$ P. Gruber ${ }^{2}$ \\ ${ }^{I}$ AIT Austrian Institute of Technology, Energy Department, Austria \\ ${ }^{2}$ Transarch - Office for Biomimetics and Transdisciplinary Architecture, \\ Austria
}

\begin{abstract}
Building envelopes made by nature or man are exposed to the same environmental conditions. Hence, the requirements in nature and of buildings are comparable. A study of analogies between natural and technical envelopes promises an overcoming of buildings being an alarming energy consumer with more than $40 \%$ of the energy demand in Europe.

The research study BioSkin targets the identification of potentials in nature that might support the energy and comfort balance in a more effective way than traditional technologies are providing now.

The first step in the study was to identify tasks of an energy efficient facade from an engineering perspective by detailed analysis of its functionalities. This specification matrix has been extended to a challenging goal: identifying potentials for a sustainable climate-adaptive energy efficient facade of the future.

This paper presents the results from the facade specification and the requirements for facades of the future. On the basis of a comparative analysis of technical and biological questions and possible solutions, a draft classification of technical tasks and biological principles has been developed. The necessary approach is described in more detail in the paper, selecting the target "passive solar strategy'.
\end{abstract}

Keywords: facade technology, sustainable building technology, passive systems, sustainable design, energy efficiency, sustainability, biomimetics, climate design. 


\section{Introduction}

According to a report by the EC-Directorate General for Energy and Transport in 2007, the biggest energy saving potential lies in residential and commercial buildings, with about $27 \%-30 \%$ less energy use or 60-90 Mtoe per year [1].

Buildings have become increasingly dependent on the energy supply with industrial development and the increase of comfort requirements. They are exposed to a wide and often conflicting variety of environmental and technical requirements. To meet the requirements of architecture, indoor comfort and technological functionality, the complexity and use of high-tech components in buildings has increased enormously. The energy use to operate these components increased accordingly.

Figure 1 shows the energetic factor of several of these components, such as heating and cooling or transmission losses and solar gains in typical office buildings, located in three climate zones in Europe, considering two building standards - a low energy building standard and a conventional standard characteristic for buildings in Vienna.

\subsection{Sustainable building design}

Modern buildings shall provide a favourable indoor climate at any time and a real-time adaptation to outdoor conditions. In today's buildings, this indoor climate has to be generated artificially. Intelligent lighting, which smoothly adapts to the outside light conditions, comfortable temperature at any time of the day and year and air ventilation without uncomfortable side-effects are just a few of the required functions in a modern building. The concurrency of the various requirements concerning the functions and system attributes has become a main challenge in the design and construction of a building.

The sustainable design approach reassembles old knowledge about climateadaptive building design and modern knowledge about high-tech climate

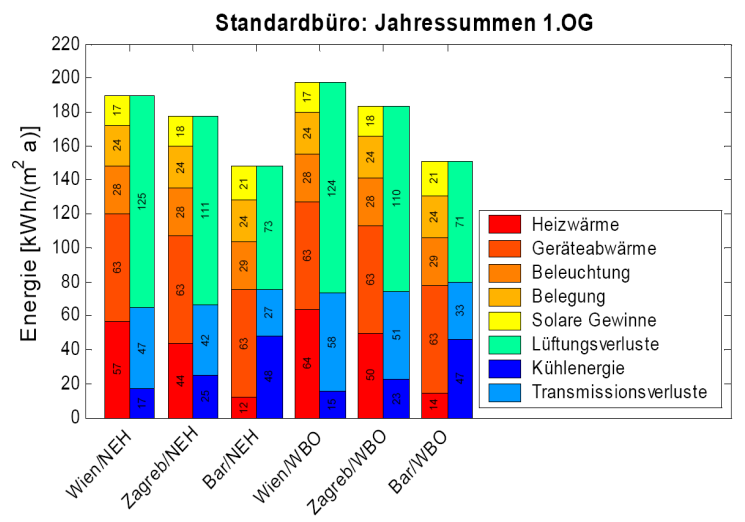

Figure 1: Comparison of energy related parameters in offices in several locations in Europe (Projekt KLIMANET, TU Graz) [2]. 
technologies, and asks for a rethinking of the methods of engineers and architects and for a sustainable approach to planning and realisation.

\subsection{Energy efficiency in the sustainable building design process}

The major criteria for energy saving measures in innovative energy efficient buildings of today can be achieved by realising the following actions:

- reduction of thermal energy losses by a thermally well insulated building envelope

- reduction of cooling energy by a good thermal quality of the building envelope, smart shading devices and use of thermal mass

- reduction of heating energy by using solar gains and high performance heating systems, geothermal or direct solar energy technologies as well as pre-conditioning of supply air via heat recovery, earth pipes, thermal zones

- reduction of electric energy use for artificial lighting by increased use of natural daylight (implementation of daylight-controlled systems and high performance lighting with sensor control technology)

- reduction of electric energy and auxiliary electricity demand by efficient energy distribution

- reduction of grey energy and environmental impact by choosing ecological building materials with a high degree of recyclability

- reduction of planning costs by integrating all technologies in a holistic design concept

- reduction of operation costs by implemented automated control strategies (building management system) and monitoring to optimize running systems

- production of electric energy by using renewable energy systems, such as photovoltaics

The planning process for energy efficient buildings passes through several stages, whereas the main tasks are the building concept (building form and orientation, fenestration configuration, etc.) provided by the architect and the energy concept (system design for cooling, heating, lightening, ventilation) elaborated by the engineer. These concepts are mainly consecutive steps, finally interlinked by adaptive control systems. Interdependencies of measures in the building and energy concepts are defined by the convergence of minimization of energy loss and needed supply for residual energy.

In a modern design process, tasks for improving the energy performance in buildings are divided into active and passive design strategies (cp. Figure 2). Building service technology, control engineering and renewable energy technologies are active 'add-on' technologies which supply energy for the building operation.

Passive strategies are focusing on the optimisation of energy efficient building constructions and materials. With the target of minimising the energy demand of buildings, passive strategies focus on the integration of constructive, 


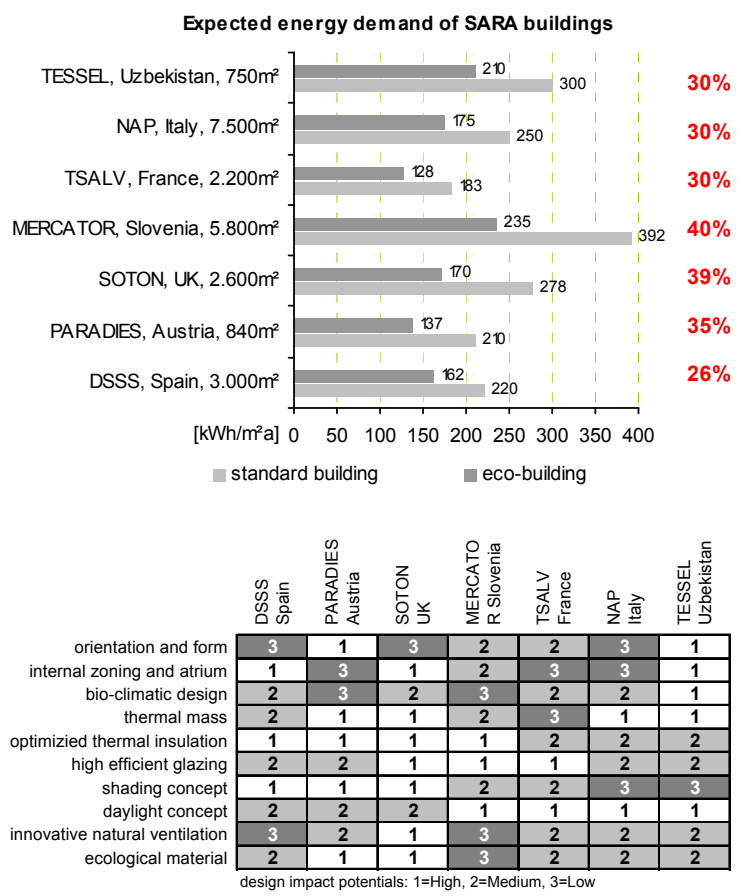

Figure 2: Expected energy demand and application list of passive design strategies in public buildings (Project SARA, AIT) [3].

structural-physical methods, materials or structures into an architectural concept, in order to lower the necessity of auxiliary energy devices. This strategy classification will be used for the investigation presented in this paper (cp. 2.2).

\section{The role of facade technology within sustainable building design strategies}

Considering the fact, that a facade has the biggest surface share of a building envelope this consequently means, that it also holds the biggest potential in gain and loss of energy and comfort; not to mention the aesthetical function of a facade as specific building component. Modern facade systems need to fulfil a wide range of different often conflicting requirements - such as maximum daylight optimisation and glare protection, thermal inertia and light-weight structure - with inverted priorities according to the seasons. Facades need to achieve a high level of energy efficiency or even contribute to the energy production of a building. 


\subsection{Recent development in facade technology}

To face the complex requirements, facade technologies have been progressing remarkably in the last years. Smart technology solutions for saving and generating energy by using the facade surface are increasing as demonstrated by existing high tech facade systems. General tendencies are shown in Table 1.

Since the complexity and effort of such systems is still high and the susceptibility to dysfunctions is given, alternatives to meet a maximum of energy efficiency, adaptivity and comfort whilst using a minimum of natural resources and embodied energy are needed.

\subsection{Engineering approach for energy efficient facades}

Several characteristic passive design strategies are used for facade systems (natural ventilation, low energy cooling, passive solar design, etc.) one of which, the passive solar strategy, will be described in more detail in this paper.

Table 1: Innovations in modern facade systems (S. Gosztonyi).

\begin{tabular}{|c|c|}
\hline NEEDED FUNCTION & TRENDS AND TECHNICAL SOLUTIONS \\
\hline $\begin{array}{c}\text { MULTIFUNCTIONALITY } \\
\text { multifunctional use of facade } \\
\text { elements covering several } \\
\text { functions } \\
\text { Decentralized systems, such as } \\
\text { integrated active systems (PV, } \\
\text { ST, HVAC) }\end{array}$ & $\begin{array}{cc} & \text { MULTIFUNCTIONAL FACADES: } \\
- & \begin{array}{l}\text { Facade systems with integrated building service } \\
\text { technologies (e.g.: cooling, heating devices) for } \\
\text { decentralized energy supply }\end{array} \\
-\quad & \begin{array}{c}\text { Interactivity with environment is partly given by } \\
\text { automation technology }\end{array} \\
-\quad & \begin{array}{c}\text { Energy supply \& distribution is provided by partly } \\
\text { decentralized energy systems }\end{array}\end{array}$ \\
\hline $\begin{array}{c}\text { SMART ENERGY } \\
\text { EFFICIENT MATERIALS } \\
\text { e.g. glazing and insulation } \\
\text { material } \\
\text { Self-X mechanism: functional } \\
\text { materials with embedded } \\
\text { sensor/control devices (e.g.: self- } \\
\quad \text { adaptive material) }\end{array}$ & $\begin{array}{c}\text { SMART FUNCTIONAL MATERIALS: } \\
-\quad \text { Smart building materials (PCM, electro-chromic } \\
\text { glazing, etc.) which are fully integrated into building } \\
\text { envelope and replace conventional building elements } \\
\text { and control devices } \\
-\quad \frac{\text { Intelligent Self-X-mechanism of material adapting to }}{\text { changing climate conditions by using embedded }} \\
\text { activators/sensors }\end{array}$ \\
\hline $\begin{array}{c}\text { USE OF RENEWABLE } \\
\text { ENERGY SYSTEMS } \\
\text { decentralized energy generation } \\
\text { by solar energy systems }\end{array}$ & $\begin{array}{cc}\text { ENERGY FACADES: } \\
-\quad \text { Energy generating facades with integrated solar energy } \\
\text { systems (photovoltaic, solar thermal) } \\
-\quad \text { Multifunctionality of solar systems by replacement of } \\
\text { constructive elements of the building envelope } \\
-\quad \begin{array}{c}\text { Control of energy supply \& distribution is usually } \\
\text { provided by centralized energy management system }\end{array} \\
\end{array}$ \\
\hline $\begin{array}{l}\text { ADAPTIVITY OF ACTIVE } \\
\text { FACADE ELEMENTS } \\
\text { adaptive building devices } \\
\text { Use of passive natural effects: } \\
\text { natural cooling and ventilation } \\
\text { concepts (facade systems, earth } \\
\text { pipe collectors, etc.) }\end{array}$ & $\begin{array}{cc}\text { ADAPTIVE F FCADES / INTELLIGENT FACADES: } \\
-\quad \text { Responsive building elements (active shading systems, } \\
\text { daylight systems, etc.), fully integrated in building } \\
\text { envelope, replacing conventional building elements } \\
-\quad \text { Interactivity with environmental conditions by facade- } \\
\text { integrated control and sensor technology in the facade } \\
-\quad \text { Adaptivity provided by integrated intelligent control } \\
\text { system which adapts to climate by integrated sensors }\end{array}$ \\
\hline
\end{tabular}




\subsubsection{Passive solar strategy}

The goal is to optimize the passive solar gains of buildings to a required degree. The use of solar radiation has an inverted pattern in the course of one year - in winter, a maximum of solar gains is aspired and in summer, solar gains are avoided.

Analysing the effects of passive solar gains, the following impact factors need to be considered: The glazing quality (fixed value: U-value, g-value, $\tau$-value), fenestration configuration and orientation, shading devices (changeable value: shading coefficient, position) and thermal mass (fixed thermal absorbing and storing properties within the building). Finally, the energy efficiency in regards to passive solar gains is depending on interacting environmental and comfort requirements, as demonstrated in Figure 3.

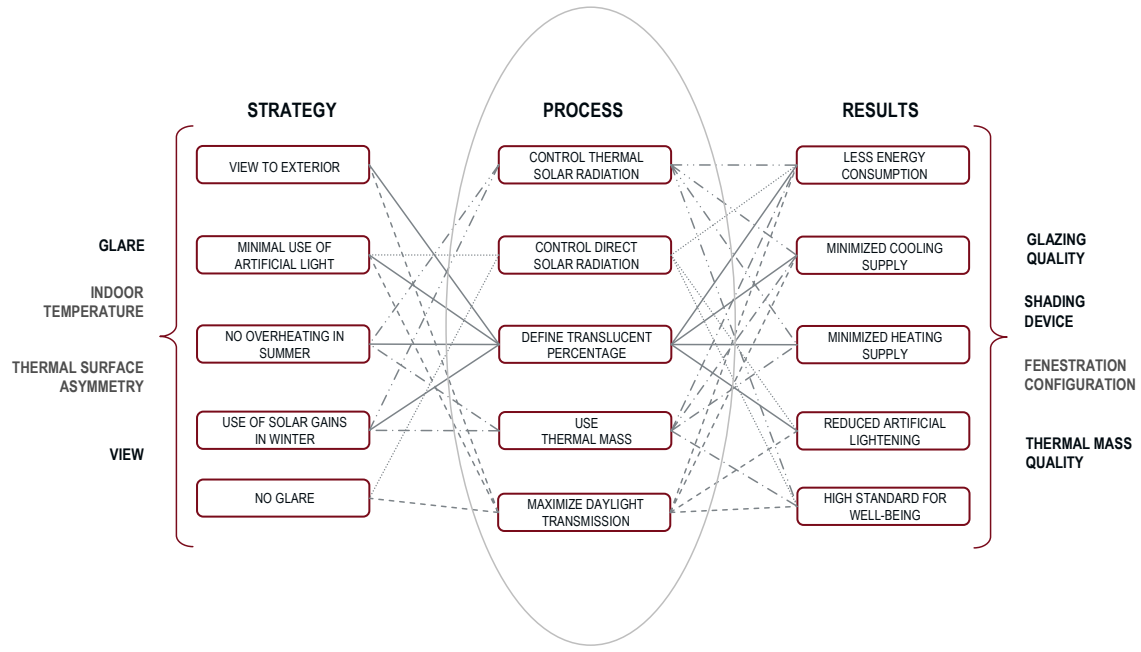

Figure 3: Interdependencies of passive solar measures and results (Project BioSkin, S. Gosztonyi).
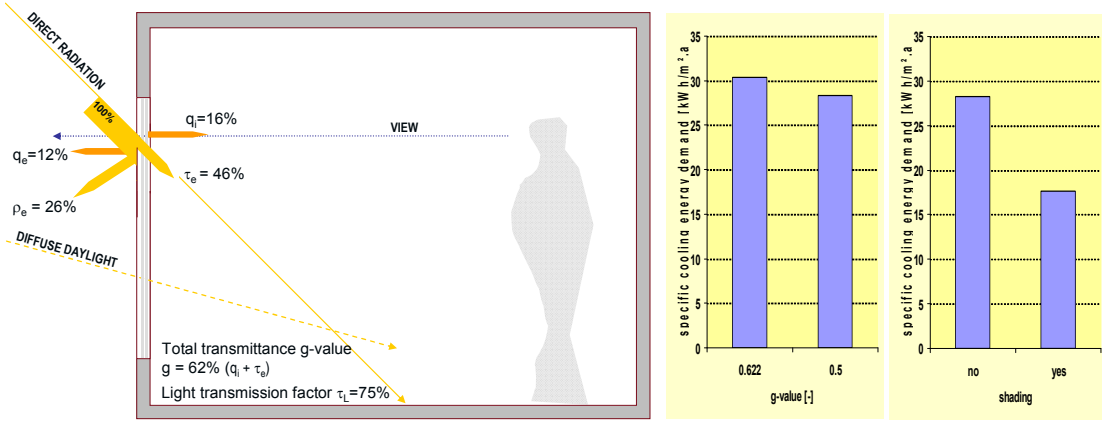

Figure 4: Influence of external shading and various g-values on specific cooling energy demand of a reference building (Project SARA, AIT [3]). 
Figure 4 shows for instance the impact on cooling energy demand by the use of shading devices and different values of total solar energy transmittance (gvalues of glazing). The trouble lies in the fixed physical properties of the building components, which will be defined in the design process based on standardized calculations. The required comfort over a year can only be satisfied by additional devices such as cooling systems, which cause an additional need for energy.

\section{Targeting bio-inspired energy efficient facade technology}

Building envelopes made by nature or man are exposed to the same environmental conditions. Hence, the requirements in nature and of buildings are comparable. A study of analogies between natural and technical envelopes promises an overcoming of intrinsic barriers in the planning of building envelopes. In biology, innovative solutions which have evolved during millions of years of evolution with the goal of system optimisation can be found. This pool of ideas will be used to find sustainable energy saving solutions which are reliable in maintenance, minimized in resource use and maximized for comfort. 'BioSkin - research potentials for bio-inspired energy-efficient facade technology', a running research study led by AIT (Austrian Institute of Technology), is targeted at the identification of sustainable energy saving potentials in nature which support the energy and comfort balance of facades in a more effective way than facade technologies are providing now.

The study intends to identify strategic research fields and intersections of innovative facade technologies and biomimetics to enable sustainable solutions for climate-adaptive and energy efficient facades systems of the future. BioSkin started in March 2009 and will be completed by May 2011. The BioSkin project team is supported by an international interdisciplinary expert team [4] with the background of biomimetics, biology, ecology and facade technology. The expert team will evaluate each process step in the project and support the progress with their profound knowledge.

\subsection{Vision for sustainable adaptive energy efficient facades of the future}

The first step in the project BioSkin was the specification of innovative facade elements and functions (Status Quo and future demand) and the definition for a "sustainable pro-active facade of the future", both serving as a basic reference for the later survey for analogies in nature (see Figure 5). The vision definition has been elaborated by expert interviews, screening of papers and results from scientific projects done at AIT.

The visionary facade concept aims at the following attributes:

- Climate-adaptive and sustainable (for environment and humans)

- energy efficient and energy active

- multifunctional and modular

- smart and communicative 


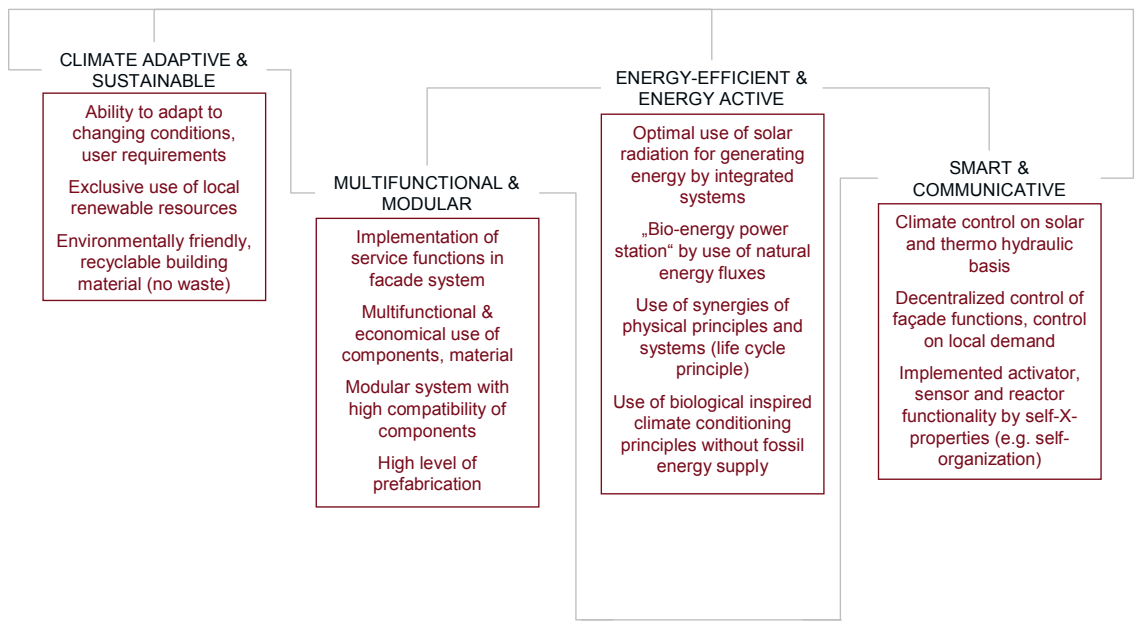

Figure 5: BioSkin - vision for sustainable pro-active facade of the future (Project BioSkin, S. Gosztonyi).

\subsection{Approach and methodology for the facade specification}

The identification of the technical functions for an energy efficient facade from the engineering perspective has been conducted by AIT using detailed analysis from scientific planning support projects and dynamic thermal or fluid simulation results of buildings. This specification brought up a challenging aspect: The definition of needs and necessary functionalities for energy efficiency and comfort. A facade matrix shown in 3.3 summarizes the complex view on achieving energy efficiency by engineering and compares this with natural solutions.

\subsection{Bio-inspired perspective: functional facade matrix and selection}

With the identification of the technical functions for an innovative facade of the future, a specification matrix was elaborated, divided in parameters (key classification), requirements and targets (sub-classifications) and applied questions, which are the basis for the survey. About 40 technical aspects or questions derived from a technical wish list; a summary is shown in Table 2.

\subsubsection{Passive solar strategy}

Concentrating now on the passive solar strategies again and on the qualities of solar radiation transmission through translucent envelopes, respectively, three main targets were identified for the facade of the future: (I) maximal transmission of light, (II) selective transmission of light, and (III) selective transmission of thermal solar radiation.

The energy-saving benefits of these targets stand out from the diverse functionalities a facade of the future must provide. They also promise innovative potentials for a sustainable optimisation process. The most effective benefits are: 
- reduction of artificial lighting, saving of energy for lighting, cooling (capital cost, maintenance, technology);

- high visual comfort by maximal use of "natural light sources", avoidance of glare;

- $\quad$ high thermal comfort by protecting from overheating, gaining passive solar energy.

A challenging step was the formulation of general questions from the technical requirements which serves as basis for interdisciplinary expert interviews and meta-search in biomimetic databases. The terminology from the building technology needed to get transferred step by step to a comprehensible terminology valid in biology: 'biologized questions' were defined to translate technical questions into biological search fields.

A detailed list of the applied technical goals concerned with passive solar strategies (daylight, solar radiation) and the transferred 'biologized' questions is shown in the Table 3.

\subsection{First results: comparison of biological and technical principles for facades}

On the basis of the facade matrix results as presented above, a functional classification of identified biological principles and allocation to technical targets

Table 2: $\quad$ Facade specification matrix - summary of technical requirements (Project BioSkin, S. Gosztonyi, M. Brychta).

\begin{tabular}{|c|c|c|c|c|}
\hline \multirow{2}{*}{\multicolumn{5}{|c|}{ SOLAR RADIATION / DAYLIGHT }} \\
\hline & & & & \\
\hline & Day light use & $\begin{array}{l}\text { Warranty of highly efficient day } \\
\text { light use }\end{array}$ & Transmit light at maximum & $\begin{array}{l}\text { Preservation of colour spectrum (1), Preservation of } \\
\text { luminousity (2), maximal use of light resources (3), } \\
\text { qualitative light generation (4) }\end{array}$ \\
\hline & \multirow[t]{2}{*}{ Day light use } & $\begin{array}{l}\text { Warranty of highly efficient day } \\
\text { light use }\end{array}$ & Guide/trace light & Constant distribution (5), Tracing/directing light (8) \\
\hline & & Warranty of optimal shading & Transmit light selectively & $\begin{array}{l}\text { Constant distribution (5), Changing of transmission factor } \\
(6,7),\end{array}$ \\
\hline \multicolumn{5}{|c|}{ HEAT PROTECTION } \\
\hline & Heat protection & $\begin{array}{l}\text { Warranty of high-efficient heat } \\
\text { protection at transparent building } \\
\text { components }\end{array}$ & $\begin{array}{l}\text { Selective transmission of heat } \\
\text { radiation }\end{array}$ & $\begin{array}{l}\text { Filterung/reflecion of thermal heat radiation (9), absportion } \\
\text { of heat radiation of semitransparent (thermal storing) } \\
\text { material (10) }\end{array}$ \\
\hline & Thermal Insulation & \begin{tabular}{|l|} 
Warranty of high-efficient heat \\
protection at opaque building \\
components
\end{tabular} & Efficient thermal insulation & Heat insulation quality via material, structures $(11,12)$ \\
\hline & $\begin{array}{l}\text { Constant indoor } \\
\text { temperature }\end{array}$ & $\begin{array}{l}\text { Use of thermal mass / Application } \\
\text { of thermal storage mass }\end{array}$ & $\begin{array}{l}\text { Management of constant indoor } \\
\text { temperature }\end{array}$ & $\begin{array}{l}\text { High efficient heat storing attributes of opaque / } \\
\text { translucent materials and structures }(15,16,17)\end{array}$ \\
\hline \multicolumn{5}{|c|}{ GAS EXCHANGE } \\
\hline & \multirow{2}{*}{\begin{tabular}{|l|} 
Natural ventilation \\
Energy efficient gas \\
exchange
\end{tabular}} & $\begin{array}{l}\text { (Passive) air ventilation with heat } \\
\text { recovery }\end{array}$ & $\begin{array}{l}\text { Sufficient air exchange without heat } \\
\text { loss }\end{array}$ & $\begin{array}{l}\text { Air exchange via structural / material attributes }(18,19) \text {, } \\
\text { air exchange via physical effects }(20,21), \\
\text { air tracing/directing abilities }(22)\end{array}$ \\
\hline & & $\begin{array}{l}\text { Warranty of energy-efficient air } \\
\text { exchange }\end{array}$ & $\begin{array}{l}\text { Reduction of air flow to a energy } \\
\text { efficient minimum }\end{array}$ & $\begin{array}{l}\text { Reduction of air exchange through infiltration, openings } \\
(13,14)\end{array}$ \\
\hline \multicolumn{5}{|c|}{ CONDITIONING INDOOR CLIMATE } \\
\hline & \multirow{2}{*}{$\begin{array}{l}\text { Natural cooling } \\
\text { Maintaince of } \\
\text { humidity }\end{array}$} & \multirow{2}{*}{$\begin{array}{l}\text { Moderate indoor comfort at } \\
\text { changing outdoor conditions } \\
\text { Moderate indoor comfort }\end{array}$} & $\begin{array}{l}\text { Generate (passive) cooling without } \\
\text { auxiliary energy }\end{array}$ & $\begin{array}{l}\text { Cooling via radiation }(23,26) \text {, cooling via air flow }(24,26) \text {, } \\
\text { cooling via evaporation }(25)\end{array}$ \\
\hline & & & regulate / maintain humidity & $\begin{array}{l}\text { Humidity regulation via controllable storage and disposal } \\
\text { (27) }\end{array}$ \\
\hline \multicolumn{5}{|l|}{ ENERGY } \\
\hline \multirow{3}{*}{$2: y^{\circ}$} & Energy generation & \multirow[b]{2}{*}{$\begin{array}{l}\text { Reliable energy generation from } \\
\text { local renewable energy source }\end{array}$} & \multirow[b]{2}{*}{ regenerative energy production } & \multirow{2}{*}{$\begin{array}{l}\text { Use of direct/indirect solar radiation }(28,29) \text {, Osmosis } \\
\text { (30), use of wind power (31), use of energy producing } \\
\text { effects (32), use of geothermal power (33) }\end{array}$} \\
\hline & Energy conversion & & & \\
\hline & Energy transport & $\begin{array}{l}\text { Supply and distribution of energy } \\
\text { (heat, light, electricity) without loss }\end{array}$ & $\begin{array}{l}\text { transport of energy without loss and } \\
\text { support of supply energy }\end{array}$ & $\begin{array}{l}\text { Light transport (34), heat transport (36), water transport } \\
\text { (37) }\end{array}$ \\
\hline
\end{tabular}


Table 3: Facade specification matrix - technical requirements for solar radiation transmission through envelopes (Project BioSkin, S. Gosztonyi, P. Gruber).

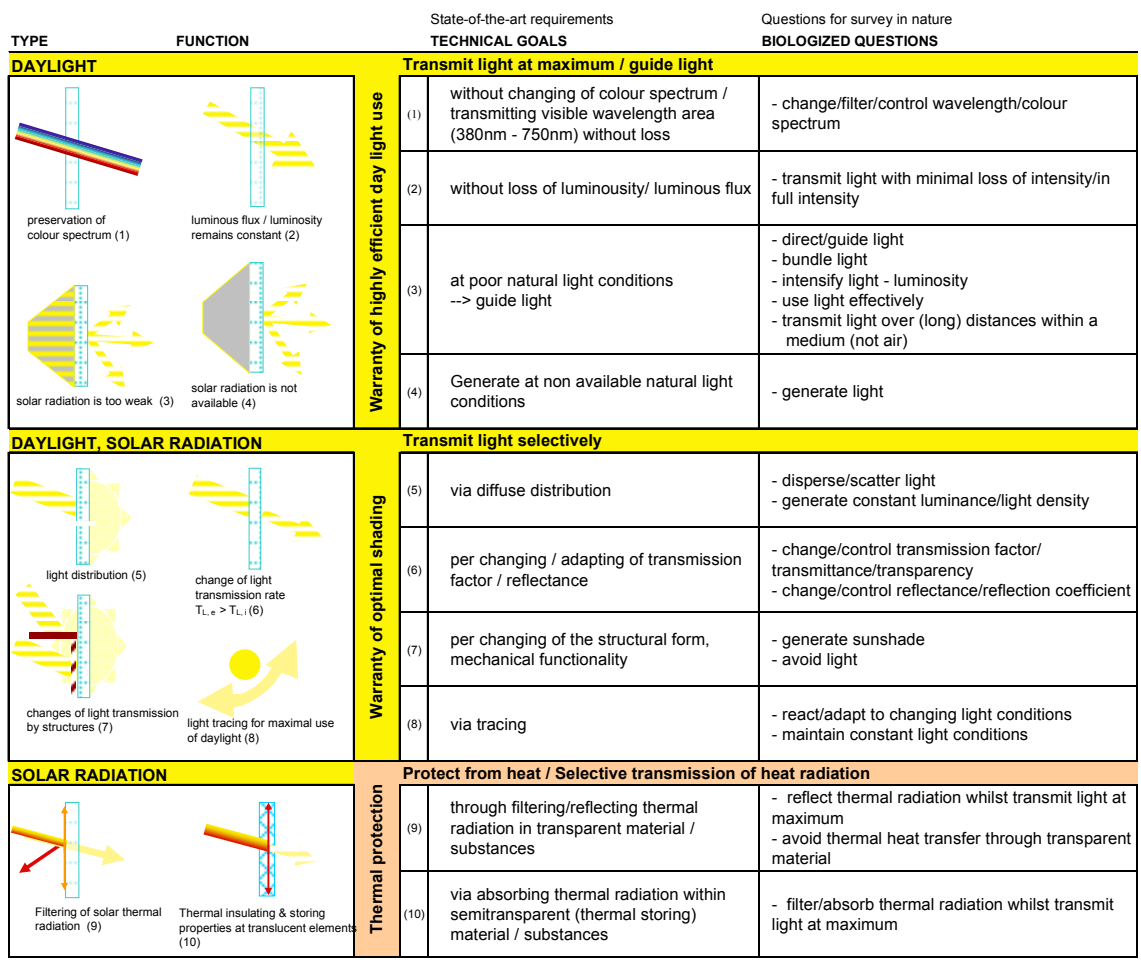

is in elaboration at the moment. To select the most promising principles, the most effective technical targets for energy savings needed to be selected. According to the recent analysis results, these will be:

- daylight use, natural cooling, natural gas exchange (ventilation).

Figure 6 presents a draft for a possible process from the technical target to biological principles.

\section{Outlook}

A revision of the 'biologized' questions and of the first draft of adjunctive examples from nature is currently in process. This will serve as a basis for the elaboration of 'biological data sheets' of the most effective paradigms of biological materials, processes and structures in relation to the specification for innovative facade systems.

Serving as a basis for the final selection of promising biological role models, the most effective technical parameters with the highest energy saving ratio are currently under investigation and will be presented at the next expert meeting end of March 2010. 


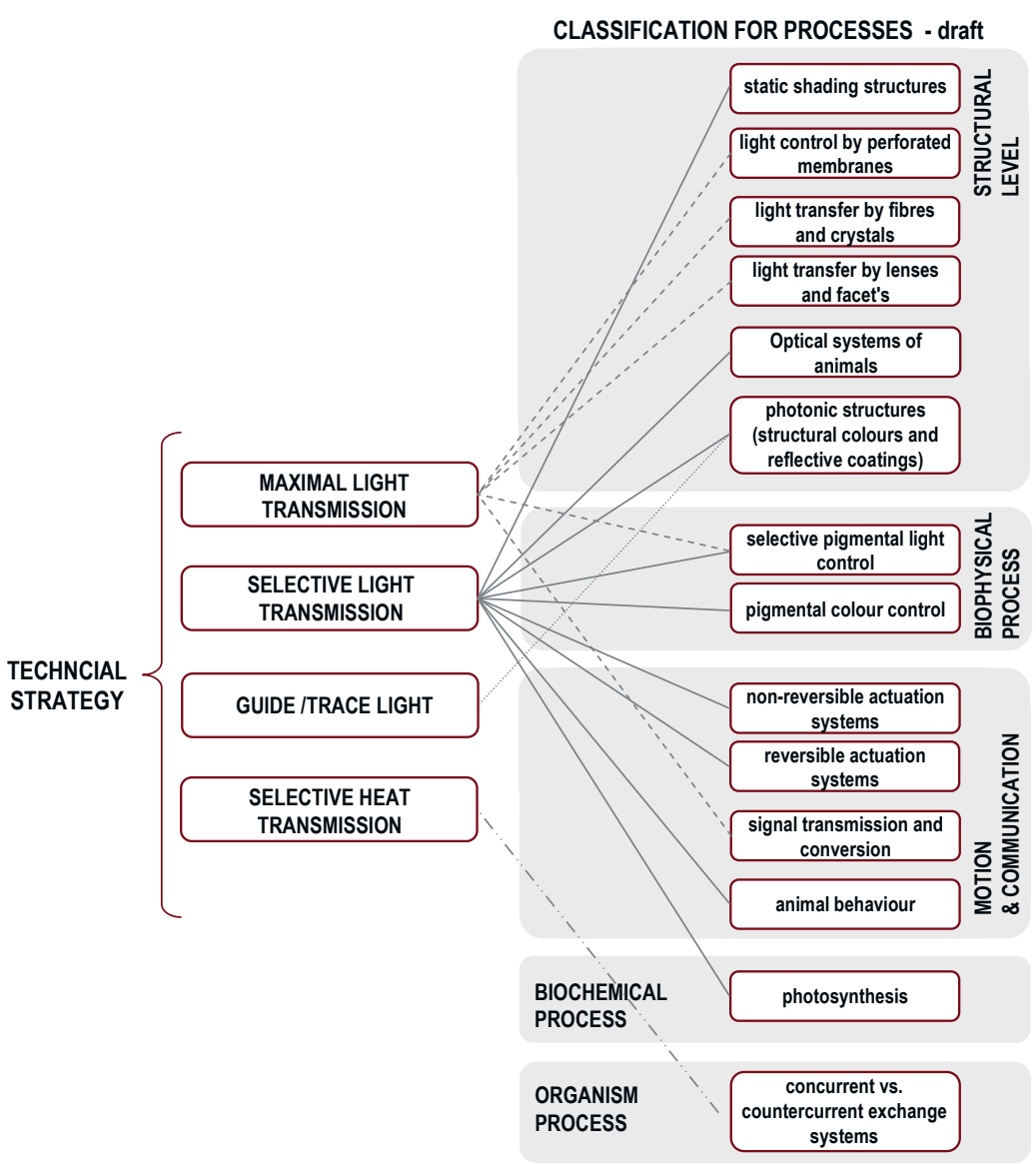

Figure 6: Draft results of biological potentials for technical functions. Target: passive solar strategy (Project BioSkin, S. Gosztonyi).

Depending on the information quality of the identified biological data, the most promising principles will be translated to facade concept drafts. Detailed analyses of the effects on energy efficiency, the interdependencies and functionalities within the facade specification, shall support the identification of innovative solutions for facades of the future. It is further expected to get new perspectives for a holistic approach of the integrative building design. Currently, the transferability of biosystems for facades (e.g. self-organisation, energy flux balance, action-reaction, life cycle) is under investigation.

\section{Acknowledgements}

The BioSkin project team are DI Susanne Gosztonyi, DI Markus Brychta and Stephan Richter BSc at the AIT Austrian Institute of Technology, Department 
Energy, Giefinggasse 2, 1210 Vienna, Austria (Contact: S. Gosztonyi, susanne.gosztonyi@ait.ac.at) and DI Dr. Petra Gruber at Transarch - Office for Biomimetics and Transdisciplinary Architecture, Zentagasse 38/1, 1050 Vienna, Austria (peg@transarch.org). The project website address is www.bionicfacades.net.

\section{References}

[1] EC-DG for Energy and Transport, 2020 vision: Saving our energy, published by EC, ISBN 92-79-03629-7, 2007.

[2] KLIMANET - Expertennetzwerk Solare Klimatisierung, National technology transfer project within programme portec-Net plus (TIG), 2005.

[3] Gosztonyi, S., Preisler, A., Challenging the public building sector: Optimization of energy performance by sustainable strategies in SARA, International conference CISBAT 2007, Lausanne, 2007.

[4] BioSkin supporting expert team: Prof. George Jeronimidis, University of Reading, UK; Prof. Thomas Speck, Universität Freiburg, DE; Prof. Sergio Altomonte, University of Nottingham, UK; Dr. Susanne Geissler, Austrian Energy Agency, AT 